Asian ACADEmy of

Management Journal

of ACCOUNTing

and FinanCE

\title{
THE EFFECT OF INVESTOR SENTIMENT ON STOCK RETURNS: INSIGHT FROM EMERGING ASIAN MARKETS
}

\author{
Shangkari V. Anusakumar ${ }^{1}$, Ruhani $\mathrm{Ali}^{2 *}$ and Hooy Chee $\mathrm{Wooi}^{3}$ \\ ${ }^{1,3}$ School of Management, Universiti Sains Malaysia, \\ 11800 USM, Pulau Pinang, Malaysia \\ ${ }^{2}$ Graduate School of Business, Universiti Sains Malaysia \\ 11800 USM, Pulau Pinang, Malaysia \\ *Corresponding author: ruhani@usm.my
}

\begin{abstract}
This paper investigates the link between investor sentiment and stock returns in emerging Asian markets. Two dimensions of sentiment are examined: stock specific sentiment and market wide sentiment. Using panel regression with firm fixed effects, we show that stock specific sentiment strongly and positively affects stock returns after controlling for firm characteristics. Overall, there is a positive relationship between market wide sentiment and returns but the relationship does not hold at the country level. For individual countries, we detect substantial country-to-country variations in the influence of market wide sentiment on returns. The evidence also suggests that stock specific sentiment may have a greater influence on returns than market specific sentiment. Furthermore, the effect of investor sentiment on stock returns in emerging Asian markets generally persists after accounting for macroeconomic factors.
\end{abstract}

Keywords: Investor sentiment, optimism and pessimism, stock returns, market sentiment, emerging markets

Publication date: 30 August 2017

To cite this article: Anusakumar, S. V., Ali, R., \& Hooy, C. W.(2017). The effect of investor sentiment on stock returns: Insight from emerging Asian markets. Asian Academy of Management Journal of Accounting and Finance, 13(1), 159-178. https://doi.org/10.21315/aamjaf2017.13.1.7

To link to this article: https://doi.org/10.21315/aamjaf2017.13.1.7

(C) Asian Academy of Management and Penerbit Universiti Sains Malaysia, 2017. This work is licensed under the terms of the Creative Commons Attribution (CC BY) (http://creativecommons.org/licenses/by/4.0/). 


\section{INTRODUCTION}

Recent years have borne witness to a surge in sentiment ${ }^{1}$ related studies. A large number of these studies, however, take an indirect approach. The likely effect of sentiment on returns is deduced from the investigation of other variables (Kurov, 2010; Kaplanski \& Levy, 2012; Kaustia \& Knupfer, 2012) or specific events such as natural disasters (Kaplanski \& Levy, 2010; Shan \& Gong, 2012), manmade disasters (Drakos, 2010), sporting events (Chang, Chen, Chou \& Lin, 2012; Curatola, Donadelli, Kizys \& Riedel, 2016), and religious festivities (Białkowski, Etebari \& Wisniewski, 2012). The sentiment, inferred using the aforementioned methods, may not represent investor sentiment in its entirely or may misrepresent sentiment. Thus, much work is needed in the direct examination of the association between sentiment and stock returns. It is this aspect of sentiment studies that we venture into by directly examining the effect of sentiment on stock returns.

In a recent study, Aissia (2016) examine the effect of home and foreign investor sentiment in the French stock market and found that both sentiments affect stock returns. In addition, Liston (2016) document that both individual and institutional investor sentiments influence sin stocks returns. Venturing further, Tsai (2017) examine the sentiment of three different types of institutional investors (foreign investors, trust investors, and dealers) in the Taiwan stock market. In a similar manner, we extend earlier studies of sentiment by incorporating additional dimensions of sentiment: market and stock level sentiment.

Past research has largely concentrated on either the sentiment of the stock market (e.g. Miwa, 2016) or individual stocks (e.g. Sayim \& Rahman, 2015). This paper differs in that both sentiments, at the stock level and market level, are examined in relation to stock returns. Researchers thus far have relied mostly on aggregate market returns or portfolio returns (sorted based on specific characteristics such as growth) for their analysis. We use the returns of individual stocks as the dependent variable. Moreover, we use panel data for the analysis which allows us to take advantage of the data to the fullest extent. Unlike past studies, we take a long term perspective with the use of yearly instead of monthly or weekly returns. Past papers have largely concentrated on western and developed markets, especially the US stock market (e.g. Baker \& Wurgler, 2006; Lemmon \& Portniaguina, 2006; Abdelhédi-Zouch, Abbes, \& Boujelbène, 2015; Smales, 2017). Literature on emerging markets and also Asian markets are not as extensive as developed markets; we hope to simultaneously fill these gaps in literature by examining emerging Asian markets. 
In this study, we examine the link between stock returns and sentiment in 8 emerging Asian countries: Malaysia, India, Indonesia, Philippines, Taiwan, Thailand, South Korea and China. In particular we cover two different dimensions of sentiments: stock specific and market wide sentiment. As the name implies, stock specific sentiment is the sentiment for each individual stock (i.e. at the stock level.) whilst market wide sentiment refers broadly to the sentiment prevailing in the stock market (i.e. at the market level). We find that stock specific sentiment is positively related to returns even after controlling for macroeconomic factors. On the other hand, the effect of market wide sentiment on returns is country specific. However, market wide sentiment is, overall, positively related to stock returns. The evidence also suggests that stock specific sentiment may have a greater influence on returns than market specific sentiment.

\section{RELATED LITERATURE}

Sentiment is purported to affect returns as investor's optimistic or pessimism may induce mispricings to occur in the stock market. Optimism (pessimism) may drive stock prices well above (below) that warranted by the underlying fundamental value as investors overvalue (undervalue) asset prices due to optimism (pessimism). Congruent with this notion, Brown and Cliff (2004) document a strong association between sentiment and contemporaneous stock returns. Brown and Cliff (2005) find that sentiment affects mispricing in the US stock market. Chen (2011) document a negative relationship between returns and lack of confidence in the US market which indicates that low sentiment (i.e. pessimism) is associated with low returns. Focusing on a sample of hospitality firms in the US, Singal (2012) also argues that sentiment affects stock returns; the changes in sentiment were found to be correlated with the returns of hospitality firms.

However, the aforementioned mispricings do not persist for long. As succinctly noted by Chung, Hung and Yeh (2012), mispricings driven by investor sentiment is corrected in the following periods as sentiment declines and the true value of the stocks is realized. This, then, implies that investor sentiment will be negatively related to future stock returns. Research seems to support this argument. Brown and Cliff (2005) find an inverse relationship between sentiment and future returns of 25 portfolios formed based on Fama and French (1993). Fisher and Statman (2003) and Baker and Wurgler (2006) among others also document a similar association. Recently, Chung et al. (2012) find evidence that sentiment predicts returns of portfolios, formed based on specific characteristics such as size and age, in the US market. However, this predictive power is largely limited to expansion state. International evidence is provided by Schmeling (2009) using 
a sample of 18 industrialised countries. The evidence indicates that sentiment predicts future aggregate stock returns. However, the results are not universal as sentiment does not display any predictive ability in certain countries. Bathia and Bredin (2012) demonstrate that sentiment is negatively related to future aggregate stock returns in $\mathrm{G} 7$ countries.

Sentiment studies in Asian markets are sparse. Moreover, Kim and Nofsinger (2008) note that Asians may experience behavioural biases to a greater extent than people of other cultures. Thus investigating investor sentiment in Asian markets is critical as it educates global investors on the effect of sentiment on stocks and also reveals any peculiarities that may be present in Asia owing to the psychological uniqueness of Asians (i.e. higher propensity to experience cognitive biases). Chen, Chen and Lee (2013) investigate the effect of sentiment in Asian markets. It should be noted that there are several key distinctions with our study in terms of study aim and design. Chen et al.'s (2013) sample consists of Asian markets but developed Asian markets such as Japan and Singapore are also included in the sample. Critically, the stock specific sentiment is not considered in the study. Moreover, the focus is solely on industry returns rather than individual stock returns.

Firm characteristics are suggested to be a critical factor in determining the extent to which sentiment affects returns. For instance, Lee, Shleifer and Thaler (1991) assert that small firms are most affected by sentiment. Baker and Wurgler (2006) suggest that stocks that are harder to value are more susceptible to the influences of sentiment. Concentrating on size and market wide sentiment, Lemmon and Portniaguina (2006) construct a portfolio with short position on small stocks and long position on large stocks in the US market. When sentiment is high (low), the returns for small stocks are found to be lower (higher) than large stocks in the following period. However, Brown and Cliff (2004) do not find any such increased tendency for sentiment to affect returns of small stocks. In addition, Berger and Turtle (2012) document that sentiment has greater effect on stocks with specific firm characteristics especially firms that are transparent whereas Zhu and Niu (2016) suggest that firms with high information uncertainties are more affected by sentiment. In a recent study, Tuyon, Ahmad and Matahir (2016) note that degree to which sentiment affects stock prices may differ based on firm size. Accordingly, we include firm-level controls to incorporate this aspect in our analysis. 


\section{DATA AND METHODOLOGY}

\section{Sample and Return Data}

We investigate the effect of sentiment on stock returns in emerging Asian markets for the period January 2001 to December 2011. For the purpose of this study, eight countries, Malaysia, India, Indonesia, Philippines, Taiwan, Thailand, South Korea and China, are selected. We define markets as emerging based on Datastream classification to ensure a uniform segregation of the markets. Yearly stock returns are obtained for all listed ordinary stocks in the stock markets. The sample consists of 67,489 firm-year observations from 11,634 firms. As in past studies, data on stock returns, trading volume and control variables are obtained from Datastream (Ali, Ahmad, \& Anusakumar, 2011; Chen et al., 2013). All data are denominated in US currency. For each country, we winsorise all variables at the 1st and 99th percentiles to minimise the potential effects of outliers.

\section{Investor Sentiment}

We examine stock specific and market wide sentiment. Thus a consistent and reliable measure of sentiment across the sample countries is required. Survey data such as consumer confidence index, whilst a popular sentiment proxy, is not suitable for this study as the data is sparse and possibly constructed in a vastly different manner across emerging markets. Trading volume, in its capacity as a gauge of liquidity, has been suggested to be a measure of investor sentiment (Baker \& Stein, 2004). Liao, Huang and Wu (2011), Baker and Wurgler (2006) and Chen et al. (2013) among others use trading volume as a proxy for sentiment. In the interest of maintaining a consistent proxy of sentiment across markets, we adopt trading volume as measure of sentiment throughout this study.

Stock specific sentiment refers to the sentiment of individual stocks. Following Liao et al. (2011), stock specific sentiment is computed for all of the stocks in each market as follows:

$$
\text { Sentiment } S_{i, t}=\log \left(V_{i, t}\right)-\log \left(V_{i, t-1}\right)
$$

where Sentiment $S_{i, t}$ is the sentiment for stock $i$ at year $t . V_{i, t}$ is the trading volume for stock $i$ at year $t$ and $V_{i, t-1}$ is the trading volume for stock $i$ at year $t-1$.

Market wide sentiment represents the overall sentiment of the market. We measure market wide sentiment for each of the emerging markets using the trading volume of the local market indices from Datastream: 


$$
\text { Sentiment } M_{e, t}=\log \left(I V_{e, t}\right)-\log \left(I V_{e, t-1}\right)
$$

where Sentiment $M_{e, t}$ is the market wide sentiment for emerging market $e$ at year $t$. $I V_{e, t}$ is the trading volume of Datastream local market index for emerging market $e$ at year $t$ and $I V_{e, t-l}$ is the trading volume of Datastream local market index for emerging market $e$ at year $t-1$.

\section{Control Variables}

We employ two sets of controls for our analysis. Firstly, firm level controls are designed to capture the potential effects of the discrepancies in firm characteristics. Baker and Wurgler (2006) find that sentiment exerts greater influence on stocks with certain characteristics in the US stock market. In particular, small stocks, volatile stocks, unprofitable stocks, growth stocks and distressed stocks are greatly affected by sentiment. Berger and Turtle (2012) also suggest that sentiment may have a greater impact on firms with certain characteristics, which the authors term as sentiment-prone stocks. Stocks that are harder to value and arbitrage are expected to be sentiment-prone stocks. Berger and Turtle (2012) find that whilst transparent stocks are not affected much by sentiment, the returns of those that are harder to value are indeed swayed by sentiment.

We use several variables to control for such sentiment prone stocks. Similar to Baker and Wurgler (2006), we adopt a set of firm level variables comprising of firm size, book-to-market ratio, sales growth and return on equity. Firm size is the market capitalisation of the firm. Baker and Wurgler (2006) and Berger and Turtle (2012) argue that small stocks are less transparent and harder to value and are accordingly more sentiment prone than large stocks. Sales growth is the change in net sales over the net sales for the previous year. Firms with high (low) book-to-market ratio or sales growth may be associated with distress (high growth opportunities). Distressed firms would be more sentiment-prone. Firm profitability is measured by the return on equity (ROE) which is noted to be inversely related to sentiment sensitivities.

Secondly, we also include macroeconomic variables to account for differing macroeconomic conditions. This allows us, to an extent, to isolate the effect of sentiment from that of economic conditions. It may be necessary to ensure that the results obtained are not merely a reflection of variations in business-cycle. Baker and Wurgler (2006) and Lemmon and Portniaguina (2006) also consider this aspect and attempt to isolate the effect of macroeconomic factors from that of sentiment. Similarly, Schmeling (2009) also employed several macroeconomic variables in their panel regression. However, Chen et al. (2013) chose business 
cycle as the sole factor to represent macroeconomic conditions. We undertake a similar procedure as in Schmeling (2009). Specifically, our control variables market dividend yield, inflation (based on consumer price index), industrial production, money supply (M1), term spread (difference between long term bond rate and interbank or money market short term rate) and short-term interest rate.

\section{Panel Regression}

In order to examine the relationship between sentiment and stock returns, we employ a linear panel regression with firm fixed effects. Firm fixed effects controls for firm heterogeneity. We run the panel regression separately for each country in our sample and for emerging Asian markets as a whole (i.e. all 8 markets). Our basic regression can be represented as:

$$
R_{i, t}=\alpha_{i}+\gamma \text { SentimentS } S_{i, t}+\beta \text { Sentiment } M_{t}+\eta F I+\varepsilon_{i, t}
$$

where $R_{i, t}$ is the return for stock $i$ in year $t$. Sentiment $S$ and SentimentM represent the stock specific sentiment and market wide sentiment respectively. FI is the control variables for firm characteristics which are firm size, book-to-market ratio, sales growth and return on equity.

Baker and Wurgler (2006) argue that sentiment may reflect business cycle variations and correspondingly proceed to extract any component of these business cycle variations from their sentiment measures. On the other hand, Schmeling (2009) incorporate macroeconomic controls into their model in order to mitigate common risk factors. In order to address such concerns, we take an approach similar to Schmeling (2009). We include macroeconomic variables in our regression to determine if the effect of sentiment on returns is solely due to macroeconomic factors. We estimate the following equation separately for each country in our sample and also for the sample as a whole:

$$
R_{i, t}=\alpha_{i}+\gamma \text { Sentiment } S_{i, t}+\beta \text { Sentiment }_{t}+\eta F I+\phi M A+\varepsilon_{i, t}
$$

where $R_{i, t}$ is the return for stock $i$ in year $t$. Sentiment $S$ and SentimentM represent the stock specific sentiment and market wide sentiment respectively. FI is the controls for firm characteristics which are firm size, book-to-market ratio, sales growth and return on equity. $M A$ is the macroeconomic control variables which includes annual CPI inflation and dividend yield. 


\section{RESULTS}

\section{Descriptive Statistics}

The sample consists of 11,634 firms in eight countries. The data is collected over an 11-year period from 2001 to 2011. Table 1 lists the descriptive statistics for all the variables used in this study. Return is the yearly return, SentimentS is the stock specific sentiment whereas SentimentM is the market wide sentiment. SIZE, GROWTH, BM and ROE are firm level data representing firm size, sales growth, book-to-market ratio, and return on equity respectively. Dividend and inflation are the macroeconomic control variables.

As can be observed, mean values of all variables are positive. Market wide sentiment has a higher mean value than stock specific sentiment, which would suggest that investor's display greater sentiment on an overall market level than for specific stocks. However, it should be noted that variability for stock specific sentiment is greater than market wide sentiment.

Table 1

Descriptive statistics

This table reports the summary of descriptive statistics of the variables for the individual firms of 8eight Asian markets. The total sample of the 8eight markets consists of 64,308 firm-year observations from 11,634 firms over the period 2001-2011.

\begin{tabular}{lccc}
\hline Variable & Observation & Mean & Standard Deviation \\
\hline Return & 94610 & 0.0359 & 0.6656 \\
SentimentS & 87833 & 0.0198 & 0.5200 \\
SentimentM & 127973 & 0.0440 & 0.1882 \\
SIZE & 84630 & 0.2328 & 0.6359 \\
GROWTH & 100935 & 3.8047 & 2.3978 \\
BM & 79708 & 1.0051 & 1.4452 \\
ROE & 82251 & 7.8537 & 23.1095 \\
Dividend & 127974 & 2.7136 & 1.3762 \\
Inflation & 127974 & 4.8170 & 3.2521 \\
\hline
\end{tabular}

\section{Correlation}

Table 2 reports the correlation matrix. The correlation between the dependent, independent and control variables are provided. As expected, the sentiment measures are positively correlated with stock returns. Compared with market wide 
sentiment (SentimentM), stock specific sentiment (SentimentS) shows substantially greater correlation with returns. This implies that stock specific sentiment may have more influence on stock returns than market wide sentiment. As explored and discussed further, this is also reflected in regression results presented in section "Does investor sentiment affect stock returns?". With a low value of 0.0443 , there is little correlation between SentimentS and SentimentM. In the context of our study, this information offers an important insight as the low correlation suggests that the two dimensions of sentiment are in fact distinct and warrant the separate investigation accorded in our investigation.

In general, firm level variables display positive correlation with the exception of BM. Book-to-market ratio (BM) is negatively correlated with other variables and this correlation is most prominent in the case stock returns. This is to be expected as book-to-market ratio is a variable that is denominated by market price. As noted by Pontiff and Schall (1998, p. 145), "positive (negative) market return shocks will produce negative (positive) shocks to price-denominated variables". SIZE is positively correlated with SentimentS and SentimentM. The positive correlation is consistent with the findings of Brown and Cliff (2005) that there is positive relationship between sentiment and size. Furthermore, the two sentiment dimensions and the other control variables do not display a strong correlation (absolute value ranging from 0.0031 to 0.1312). As noted by Brown and Cliff (2005), the lack of substantial correlation indicates that sentiment may contain additional information (apart from the marginal overlap between the information of sentiment and controls). 


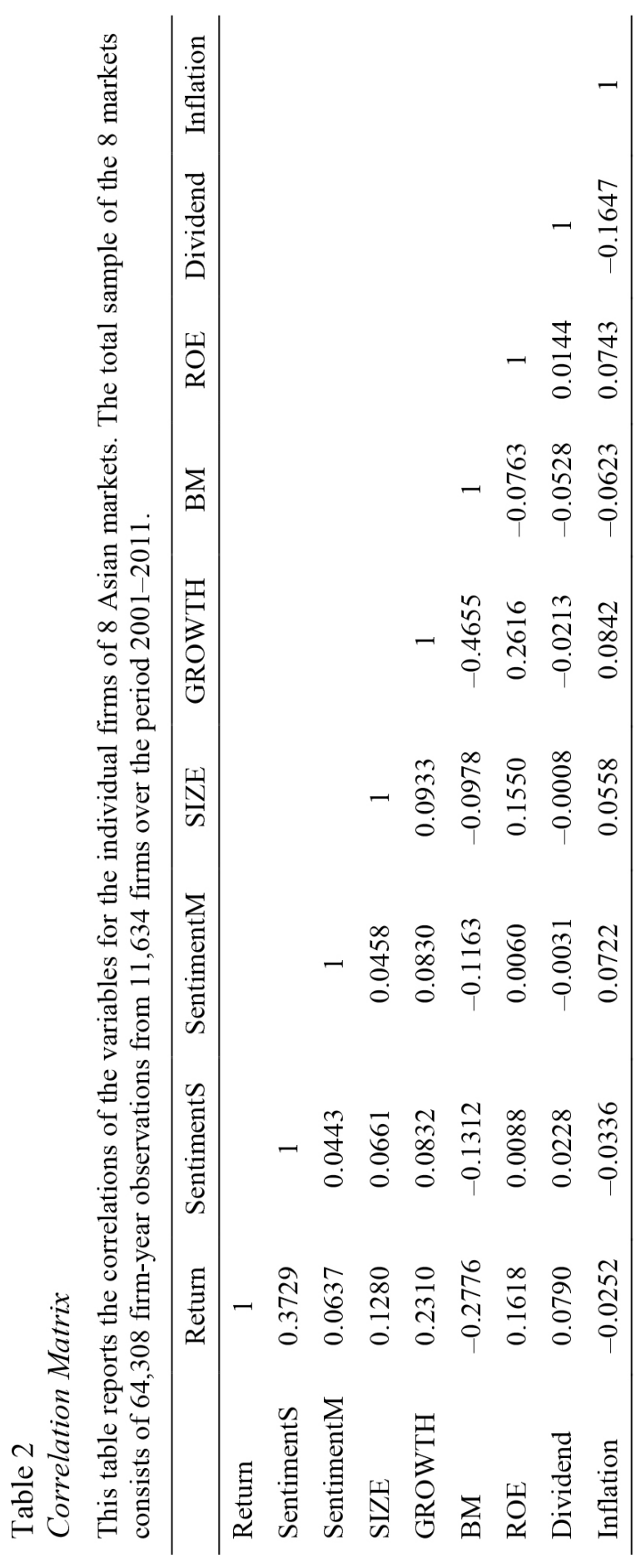




\section{Does Investor Sentiment Affect Stock Returns?}

Table 3 presents the results of the panel regression including the coefficient estimates and $\mathrm{R}^{2}$ values. We regress stock returns on stock specific sentiment and market wide sentiment and include firm fixed effects to account for firm heterogeneity. We also include firm level control variables in the regression: firm size (SIZE), sale growth (Growth), book-to-market ratio (BM), and Return on Equity (ROE). The results for the individual markets are reported sequentially in the first eight columns of the table. The last column, "Asia", represents the results for the regression using all eight emerging Asian markets. The firm clustered robust standard errors are provided in parenthesis.

Most notably, the coefficients for SentimentS are positive and statistically significant at the $1 \%$ level for all of the individual countries and also for Asia as a whole. This finding is consistent with the notion that stock specific sentiment is positively associated with stock returns. An increase in stock specific sentiment would be accompanied by an increase in stock returns. Similarly, a decrease in sentiment is followed by a decrease in returns. Based on the evidence, Indonesia seems least affected by stock specific sentiment. On the other hand, annual returns in Chinese stock market appear to be highly susceptible to sentiment at the stock level. The findings for South Korea corroborate those of Ryu, Kim and Yang (2016) wherein stock level sentiment was found to be positively related to stock market returns.

In contrast, the evidence for market wide sentiment is not as uniform as stock specific sentiment. As can be observed, India, South Korea and Taiwan have highly significant positive coefficients for SentimentM which would imply that an increase (decrease) in sentiment is associated with an increase (decrease) in stock returns. The regression result for Asia is also similar with a positive coefficient that is significant at the $1 \%$ level. The findings for these countries are largely consistent with those of Brown and Cliff (2004) and Singal (2012). Market wide sentiment has no effect in Thailand as the coefficient, though positive, is insignificant. However, the coefficients of SentimentM are significantly negative for the remaining four countries: China, Indonesia, Malaysia and Philippines. The negative coefficients indicate that sentiment is inversely related to returns. 


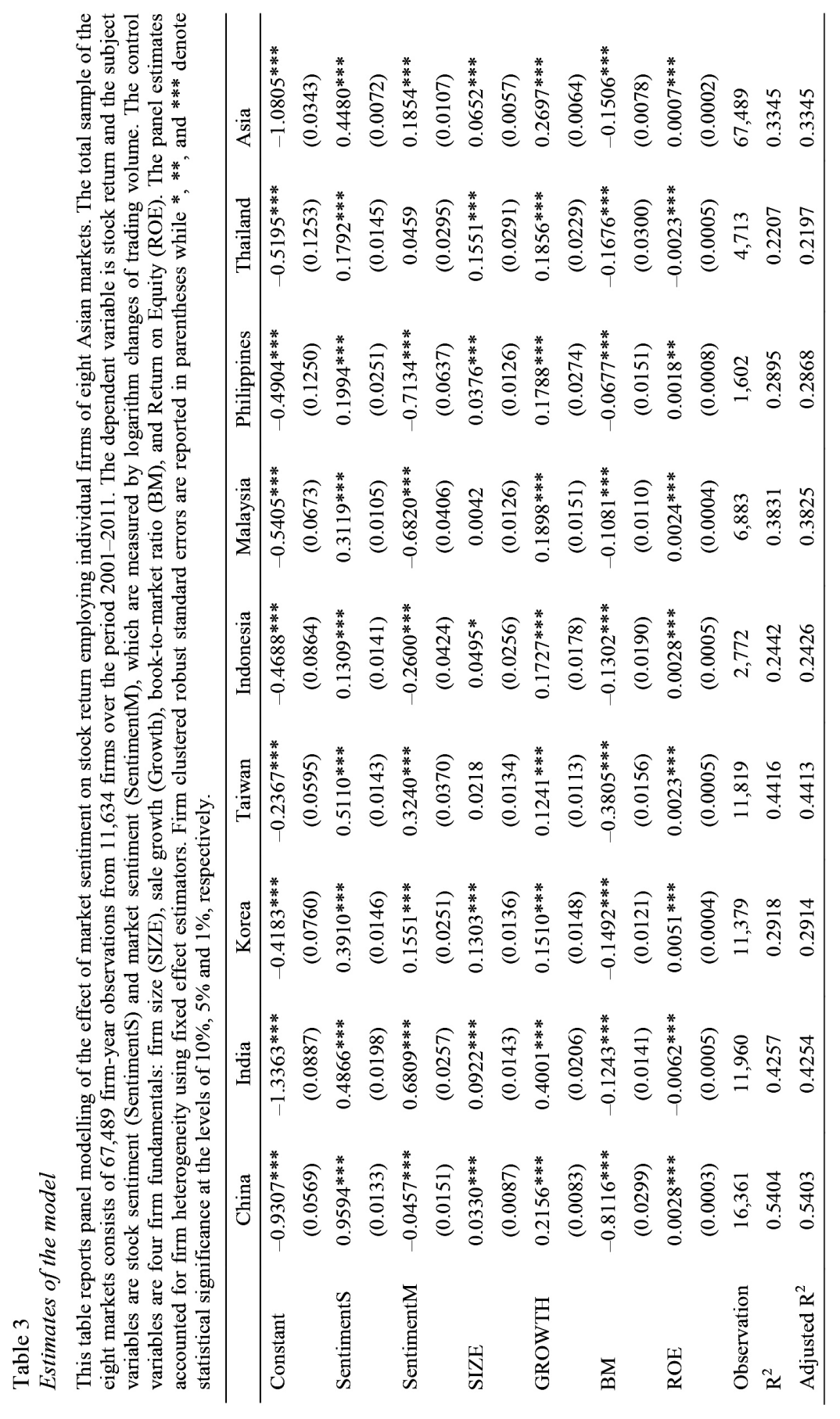


In certain countries, the two dimensions of sentiment have an equally significant and yet opposing effect on returns. For instance, stock returns in Indonesia increase following an increase in sentiment at the stock level but decline after an increase in sentiment at the market level. The absolute magnitude of the coefficients is greater for SentimentS compared to SentimentM for half of the sample countries. For Asia, the magnitude of the coefficient for SentimentS is considerably higher than SentimentM (0.4480 vs. 0.1854). Overall, our findings suggest that market wide sentiment does not have as much of an effect on stock returns as stock specific sentiment in emerging Asian markets.

For individual markets, the effect of market wide sentiment, if any, is largely dependent on the country. In this respect, our findings for market wide sentiment are congruent with Schmeling (2009). Schmeling (2009) documents that the effect of sentiment varies drastically from country to country for a sample of industrialised countries. As noted by the author, the variation seems to be unrelated to country size and location. Accordingly, we also find no readily apparent cause for the cross-country differences.

In the regression, we control for four firm characteristics which are firm size (SIZE), sale growth (Growth), book-to-market ratio (BM), and Return on Equity (ROE). With the exception of SIZE for Taiwan and Malaysia, all of the four variables enter significantly into the regressions. It appears that firm size has no effect in Taiwan and Malaysia. Moreover, the firm level control variables generally have positive coefficients for all countries and Asia. The only exception is bookto-market ratio. BM coefficients are significantly negative for all of the individual country regressions and also the regression for the whole sample (Asia). This evidence is consistent with the earlier findings of a negative correlation between $\mathrm{BM}$ and the other variables.

In general, the results in Table 3 suggest that the effect of sentiment on prices may be stronger than that of firm fundamentals. This finding might support the notion that Asians are more prone to behavioural biases than people of other cultures (Kim \& Nofsinger, 2008). However, a direct comparative study between Asian and other countries would be needed to provide a conclusive evidence.

\section{Is It Macroeconomic Factors?}

The results in Table 3 show that sentiment has a significant effect on stock returns. Nevertheless, it is may be pertinent to consider whether the results are driven macroeconomic factors or are largely due to the influence of sentiment. In this section, we take into account of the potential effects of macroeconomic variables. 
Specifically, we include six macroeconomic variables in the model: market dividend yield, inflation, industrial production, money supply, term spread and interest rate. Table 4 presents results of the regression of stock returns on stock specific sentiment and market wide sentiment after including the macroeconomic variables. As before, we retain the firm level control variables in the regression. The results for the individual markets are reported sequentially in the first eight columns of the table. The last column, 'Asia', represents the results for the regression using all 8 emerging Asian markets. The firm clustered robust standard errors are provided in parenthesis.

The coefficients for SentimentS are still positive and statistically significant at the $1 \%$ level for all of the countries and for Asia. The values of the coefficients are marginally lower than that of Table 3 but there are no substantial differences after including the macroeconomic variables. The only exception is China where the value declined from 0.9594 to 0.1425 . However, the statistical significance remains unaltered (at the $1 \%$ level). Overall, we find that stock specific sentiment retains its influence on returns. Therefore, the results obtained for SentimentS in Table 3 cannot be attributed to macroeconomic factors.

Unlike SentimentS, there are notable changes for SentimentM. Interestingly, the nature of the relationship between the variables changes for India and South Korea. As can be seen in Table 3, SentimentM is positively related to returns but a negative relationship exists when macroeconomic variables are included in the model (Table 4). A similarly drastic change can be observed for Indonesia where the negative relationship between returns and SentimentM turns to positive once we account for macroeconomic factors. For Taiwan and Philippines, the relationship between market wide sentiment and returns dissipates entirely as the coefficient of Sentiment $M$ is insignificant. This indicates that the relationship observed in Table 3 for these two countries is due the influence of macroeconomic factors. In contrast, the coefficient of SentimentM for Thailand changes from insignificant (Table 3) to significantly negative (Table 4). 


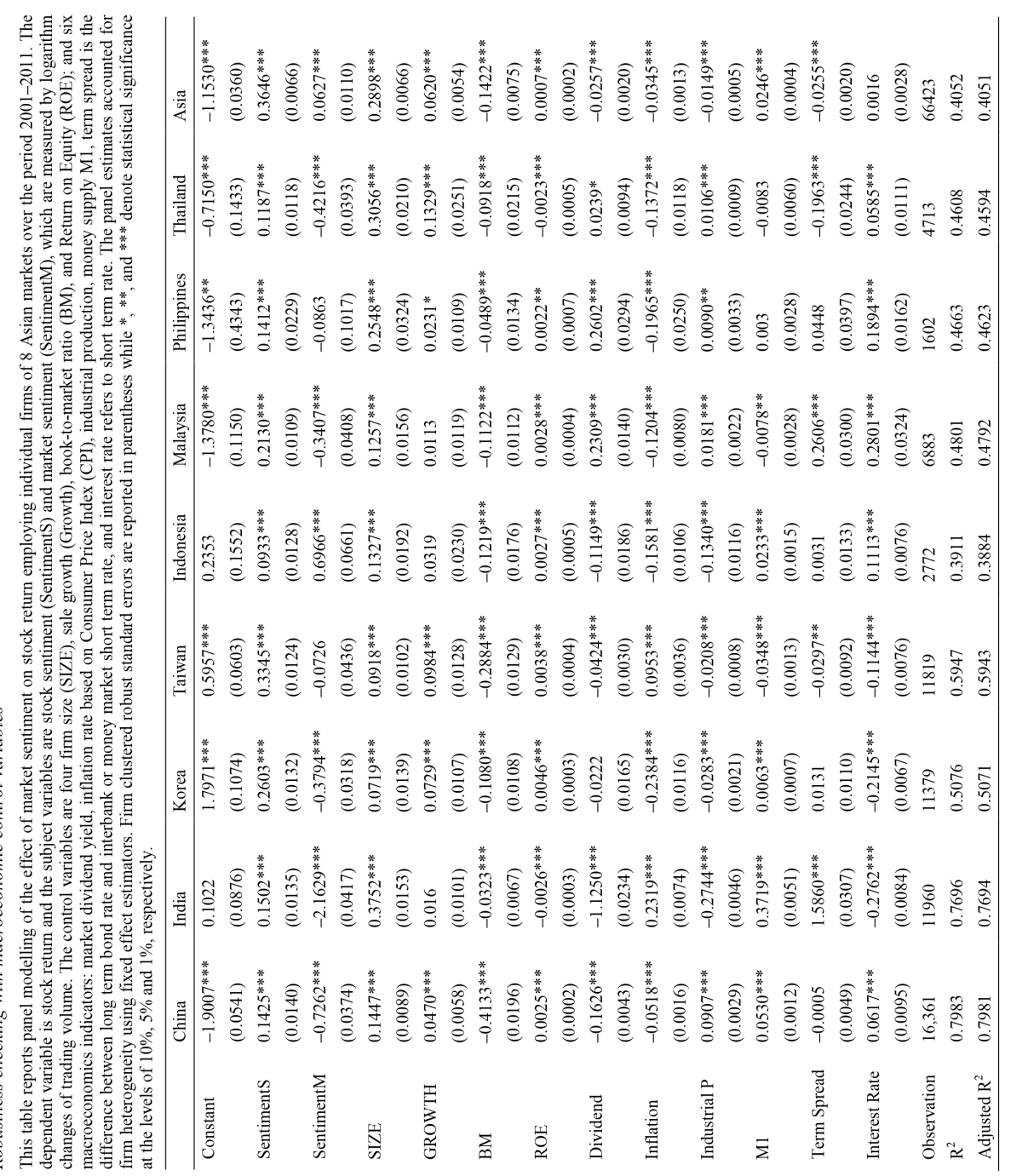


There are no substantial changes for SentimentM for China and Malaysia indicating that macroeconomic fundamentals have little bearing on the effect of sentiment on returns in these two countries. However, differences in the magnitude of the coefficients could be observed. For China, there is an increase in the absolute value of the coefficient once macroeconomic variables are included in the regression. In contrast, there is a reduction in the absolute value of the coefficient for Malaysia (from -0.6820 to -0.3407 ). Nevertheless, the coefficients are statistically significant at the $1 \%$ level regardless of whether macroeconomic variables are included in model. Likewise, SentimentM coefficients for Asia are similar before and after including macroeconomic variables in the model. Thus, the influence of market wide sentiment on returns in emerging Asian markets is, overall, unaffected by the inclusion of macroeconomic variables.

Congruent with Schmeling (2009), market wide sentiment significantly affects returns in a regression model that incorporates macroeconomic variables. The effect of sentiment also remains a largely country specific matter. It should be noted that for the overall sample (Asia), the value of coefficients and $\mathrm{R}^{2}$ do not have undergo any substantial changes. In general, the effect of sentiment on stock returns in emerging Asian markets in unaffected by macroeconomic fundamentals. Nevertheless, there are differences, for a majority of the individual countries, in the results for market wide sentiment with and without the macroeconomic control variables. Moreover, the adjusted $\mathrm{R}^{2}$ also experience an increase (Table 3 vs. Table 4) which indicates that the macroeconomic variables do hold some explanatory power. Inflation, interest rate and industrial production exert the most influence as the coefficients are statistically significant for all the countries. Taken together, the evidence highlights the importance of incorporating of macroeconomic variables in the regression model for individual countries.

\section{CONCLUSION}

In this study, we examine the link between returns and investor sentiment in emerging Asian markets. Overall, sentiment appears to be positively related to stock returns. Specifically, there is significant and positive relationship between stock specific sentiment and returns for all eight countries and for overall sample. On the other hand, we find that the effect of market wide sentiment varies vastly from country to country. Market wide sentiment is negatively related to returns for half of the sample countries. Nevertheless, a positive association can be observed for the overall sample and three of the individual countries. The evidence suggests that stock specific and market wide sentiment are distinct and in some cases, 
stock specific sentiment may exert a greater influence on returns than market wide sentiment.

This study has filled the gap in sentiment literature by examining the effect of investor sentiment on stock returns in emerging Asian markets. The results demonstrate that sentiment also affects stock returns in emerging Asian markets and reassert the importance of investor sentiment. Furthermore, we extend the literature by shedding light on the effect of two dimensions of sentiment, market wide sentiment and stock specific sentiment, on stock returns. From a practical standpoint, the findings of this paper may be relevant to investors as the results suggest that sentiment has an effect on stock prices. Additionally, we have shown that prices are influenced by two distinct sentiments: market wide and stock specific sentiment. Investors may use these findings to guide their investment decisions. Although robustness test was conducted, the study could benefit from additional tests that make use of alternative time periods, samples and sentiment proxies. In short, the paper contributes to the limited literature on investor sentiment and paves the way for future studies to conduct additional investigation on investor sentiment in Asia.

Though this study provides substantial evidence on the association between sentiment and stock returns, there are numerous aspects that could be explored. Future studies could examine the cause of the drastic cross-country variations in the effect of market wide sentiment. The relationship between stock specific sentiment and market wide sentiment also deserves further attention. In particular, the contrasting nature of the two dimensions of sentiment in certain countries is undoubtedly of interest.

\section{ACKNOWLEDGEMENTS}

The authors gratefully acknowledges the support of Universiti Sains Malaysia Research University Grant No. 1001.PPAMC.816192.

\section{NOTES}

1. There are various definitions of investor sentiment. Kurov (2010) defined investor sentiment as "the propensity to speculate" (p. 140) whereas Baker and Wurgler (2007) stated that sentiment is the "belief about future cash flows and investment risks that are not justified by the facts" (p. 120). 


\section{REFERENCES}

Abdelhédi-Zouch, M., Abbes, M. B., \& Boujelbène, Y. (2015). Volatility spillover and investor sentiment: Subprime crisis. Asian Academy of Management Journal of Accounting and Finance, 11(2), 83-101.

Aissia, D. B. (2016). Home and foreign investor sentiment and the stock returns. The Quarterly Review of Economics and Finance, 59, 71-77. https://doi.org/10.1016/j. qref.2015.06.009

Ali, R., Ahmad, Z., \& Anusakumar, S. V. (2011). Stock market overreaction and trading volume: Evidence from Malaysia. Asian Academy of Management Journal of Accounting \& Finance, 7(2), 103-119.

Baker, M., \& Stein, J. C. (2004). Market liquidity as a sentiment indicator. Journal of Financial Markets, 7(3), 271-299. https://doi.org/10.1016/j.finmar.2003.11.005

Baker, M., \& Wurgler, J. (2006). Investor sentiment and the cross-section of stock returns. Journal of Finance, 61(4), 1645-1680. https://doi.org/10.1111/j.15406261.2006.00885.x

Baker, M., \& Wurgler, J. (2007). Investor sentiment in the stock market. The Journal of Economic Perspectives, 21(2), 129-151. https://doi.org/10.1257/jep.21.2.129

Bathia, D., \& Bredin, D. (2012). An examination of investor sentiment effect on G7 stock market returns. The European Journal of Finance, 9, 1-29.

Berger, D., \& Turtle, H. J. (2012). Cross-sectional performance and investor sentiment in a multiple risk factor model. Journal of Banking \& Finance, 36(4), 1107-1121. https://doi.org/10.1016/j.jbankfin.2011.11.001

Białkowski, J., Etebari, A., \& Wisniewski, T. P. (2012). Fast profits: Investor sentiment and stock returns during Ramadan. Journal of Banking \& Finance, 36(3), 835-845. https://doi.org/10.1016/j.jbankfin.2011.09.014

Brown, G. W., \& Cliff, M. T. (2004). Investor sentiment and the near-term stock market. Journal of Empirical Finance, 11(1), 1-27. https://doi.org/10.1016/j. jempfin.2002.12.001

Brown, G. W., \& Cliff, M. T. (2005). Investor sentiment and asset valuation. Journal of Business, 78(2), 405-440. https://doi.org/10.1086/427633

Chang, S.-C., Chen, S.-S., Chou, R. K., \& Lin, Y.-H. (2012). Local sports sentiment and returns of locally headquartered stocks: A firm-level analysis. Journal of Empirical Finance, 19(3), 309-318. https://doi.org/10.1016/j.jempfin.2011.12.005

Chen, M.-P., Chen, P.-F., \& Lee, C.-C. (2013). Asymmetric effects of investor sentiment on industry stock returns: Panel data evidence. Emerging Markets Review, 14(0), 35-54. https://doi.org/10.1016/j.ememar.2012.11.001

Chen, S.-S. (2011). Lack of consumer confidence and stock returns. Journal of Empirical Finance, 18(2), 225-236. https://doi.org/10.1016/j.jempfin.2010.12.004

Chung, S.-L., Hung, C.-H., \& Yeh, C.-Y. (2012). When does investor sentiment predict stock returns? Journal of Empirical Finance, 19(2), 217-240. https://doi. org/10.1016/j.jempfin.2012.01.002

Curatola, G., Donadelli, M., Kizys, R., \& Riedel, M. (2016). Investor sentiment and sectoral stock returns: Evidence from World Cup games. Finance Research Letters, 17, 267-274. https://doi.org/10.1016/j.frl.2016.03.023 
Drakos, K. (2010). Terrorism activity, investor sentiment, and stock returns. Review of Financial Economics, 19(3), 128-135. https://doi.org/10.1016/j.rfe.2010.01.001

Fama, E. F., \& French, K. R. (1993). Common risk factors in the returns on stocks and bonds. Journal of Financial Economics, 33(1), 3-56. https://doi.org/10.1016/0304405X(93)90023-5

Fisher, K. L., \& Statman, M. (2003). Consumer confidence and stock returns. Journal of Portfolio Management, 30(1), 115-127. https://doi.org/10.3905/jpm.2003.319925

Kaplanski, G., \& Levy, H. (2010). Sentiment and stock prices: The case of aviation disasters. Journal of Financial Economics, 95(2), 174-201. https://doi.org/10.1016/j. jineco.2009.10.002

Kaplanski, G., \& Levy, H. (2012). Real estate prices: An international study of seasonality's sentiment effect. Journal of Empirical Finance, 19(1), 123-146. https://doi. org/10.1016/j.jempfin.2011.11.004

Kaustia, M., \& Knupfer, S. (2012). Peer performance and stock market entry. Journal of Financial Economics, 104(2), 321-338. https://doi.org/10.1016/j. jineco.2011.01.010

Kim, K. A., \& Nofsinger, J. R. (2008). Behavioral finance in Asia. Pacific-Basin Finance Journal, 16(1), 1-7. https://doi.org/10.1016/j.pacfin.2007.04.001

Kurov, A. (2010). Investor sentiment and the stock market's reaction to monetary policy. Journal of Banking \& Finance, 34(1), 139-149. https://doi.org/10.1016/j. jbankfin.2009.07.010

Lee, C. M. C., Shleifer, A., \& Thaler, R. H. (1991). Investor sentiment and the closed-end fund puzzle. Journal of Finance, 46(1), 75-109. https://doi. org/10.1111/j.1540-6261.1991.tb03746.x

Lemmon, M., \& Portniaguina, E. (2006). Consumer confidence and asset prices: Some empirical evidence. Review of Financial Studies, 19(4), 1499-1529. https://doi. org/10.1093/rfs/hhj038

Liao, T.-L., Huang, C.-J., \& Wu, C.-Y. (2011). Do fund managers herd to counter investor sentiment? Journal of Business Research, 64(2), 207-212. https://doi. org/10.1016/j.jbusres.2010.01.007

Liston, D. P. (2016). Sin stock returns and investor sentiment. The Quarterly Review of Economics and Finance, 59, 63-70. https://doi.org/10.1016/j.qref.2015.08.004

Miwa, K. (2016). Investor sentiment, stock mispricing, and long-term growth expectations. Research in International Business and Finance, 36, 414-423. https://doi. org/10.1016/j.ribaf.2015.10.003

Pontiff, J., \& Schall, L. D. (1998). Book-to-market ratios as predictors of market returns. Journal of Financial Economics, 49(2), 141-160. https://doi.org/10.1016/S0304405X(98)00020-8

Ryu, D., Kim, H., \& Yang, H. (2016). Investor sentiment, trading behavior and stock returns. Applied Economics Letters, 24(12), 826-830. https://doi.org/10.1080/1 3504851.2016 .1231890

Sayim, M. \& Rahman, H. (2015). The relationship between individual investor sentiment, stock return and volatility. International Journal of Emerging Markets, 10(3), 504-520. https://doi.org/10.1108/IJoEM-07-2012-0060 
Schmeling, M. (2009). Investor sentiment and stock returns: Some international evidence. Journal of Empirical Finance, 16(3), 394-408. https://doi.org/10.1016/j. jempfin.2009.01.002

Shan, L., \& Gong, S. X. (2012). Investor sentiment and stock returns: Wenchuan Earthquake. Finance Research Letters, 9(1), 36-47. https://doi.org/10.1016/j.frl.2011.07.002

Singal, M. (2012). Effect of consumer sentiment on hospitality expenditures and stock returns. International Journal of Hospitality Management, 31(2), 511-521. https://doi.org/10.1016/j.ijhm.2011.07.009

Smales, L. A. (2017). The importance of fear: investor sentiment and stock market returns. Applied Economics, 49(34), 3395-3421. https://doi.org/10.1080/00036846.2016 .1259754

Tsai, I. C. (2017). Diffusion of optimistic and pessimistic investor sentiment: An empirical study of an emerging market. International Review of Economics \& Finance, 47, 22-34. https://doi.org/10.1016/j.iref.2016.10.008

Tuyon, J., Ahmad, Z., \& Matahir, H. (2016). The role of investor sentiment in malaysian stock market. Asian Academy of Management Journal of Accounting and Finance, 12(Suppl. 1), 43-75. https://doi.org/10.21315/aamjaf2016.12.S1.3

Zhu, B., \& Niu, F. (2016). Investor sentiment, accounting information and stock price: Evidence from China. Pacific-Basin Finance Journal, 38, 125-134. https://doi. org/10.1016/j.pacfin.2016.03.010 